\title{
Health information inequalities and child healthcare: Evidence from Indonesia National Socio-Economic Survey 2013
}

\author{
Sujarwoto $^{\text {a }} *$ \\ ${ }^{a}$ Department of Public Administration University of Brawijaya
}

INFORMASI ARTIKEL

\section{Article history:}

Data submission : 10 March 2018

$1^{\text {st }}$ revision: 12 April 2018

Accepted: 03 May 2018

Available online: 12 May 2018

Keywords: health information inequalities, child healthcare, Indonesia

\begin{abstract}
This study for the first time examines the relationship between health information inequalities and child healthcare access in Indonesia, a developing country has been cited as one biggest emerging Internet users in the world. Data come from the Indonesian National Socio-Economic Survey (Susenas) 2013, which comprises 1.25 million individuals, 250 thousands households, and 497 districts. The results of descriptive and instrumental variable analysis indicate trend of widening disparities across socio-economic status and geographical areas in Internet and child immunisation access. A strong evidence for the causal flow running from a mother's access to Internet to child immunisation is found. All instruments are highly correlated with mother's access to Internet but uncorrelated with child immunisation. Supply factors across districts - particularly village health posts (posyandu) - are associated with child immunisation. The results are robust against individual, household and district socio-economic characteristics associated with child immunisation access. The results suggest that increasing mother's access to Internet may bridge child immunisation disparities in Indonesia.
\end{abstract}

2018 FIA UB. All rights reserved.

\section{Introduction}

The effect of various forms of inequality on health outcomes has been the focal point of numerous studies in social epidemiology in last two decades (Subramanian et al. 2001, Lohner et al. 2001, Kawachi et al. 2003). Most studies have examined the effect of income inequality on health (Subramanian et al. 2001, Lohner et al. 2001, Kawachi et al. 2003). There is much evidence on the detrimental effect of income inequality on both physical and mental health (Kawachi et al. 2003). Other studies have focused on the relation of inequality in the form of social disparities such as gender, race and class on health outcomes (Williams \& Jackson, 2004). These studies conclude that black and low class people generally have less healthy than white and high class people (Williams \& Jackson, 2004).
Some studies have examined the link between spatial inequality and health outcomes (Weeks et al. 2014). These studies show how various form of spatial inequality are related with lower physical and mental health within neighbourhoods or community within regions (Jennings \& Barbosa 2009, Weeks et al. 2014).

Recently, scholars and policy makers warn about digital divide as a new form of social inequality resulted from unequal access and use of the Internet within society (Norris 2001, World Bank 2014). World Bank (2014) highlights this issue as main theme of the coming World Development Report 2016 as they point out "...the Internet, while accelerating growth, can also accentuate existing disparities...". In the health sector, Viswanath (2014) points out an issue of an unhealthy digital divide, which refers to detrimental health 
consequences due to the gap between those who have access the Internet on those who have not. The Internet has the greatest potential to promote health and prevent disease for individuals and communities through health information technology (HIT) (Berhardt 2000). Unequal access of the Internet thus may widen the disparities of health for individuals, communities and entire societies (Wyatt et al. 2005, Korp 2006, Viswanath 2014). As Barry (2013) points out that today the Internet can help mean the difference between sickness and health or live and death.

\section{Theory}

Three main pathways are mentioned in the literature to explain the link between digital divide and child health. First, lack of access to the Internet may hinder parents to access useful heath information provided in the Internet. Today, various information for maintaining children health is delivered through the Internet, such as healthy diet, child immunisation, safety pregnancy, healthy diet, and physical activities. Parents can use website to help them to track their diet, weight, and physical activities during pregnancy (Bernhardt \& Felter 2004) as well as get information for their children such as child immunisation (Smith et al. 2009). Bernhardt and Felter (2004) found that women appear to be high information seekers during pregnancy and the first few years following delivery, and this period represents an important window of time for providing online health information. Hence, The Internet offers a limitless resource for information about health. Thus, mothers with lack access to the Internet may not get the benefits of such health information and therefore they may have less knowledge and skills to maintain their own health as well as their children health. For example, mothers with lack access to the Internet may have less knowledge about the importance of immunisation for their children. They may also have less information to get immunisation services for their children.

Second, lack of access to the Internet may hinder people to access health care provided in the Internet. The Internet help patients to communicate with public health and medical practitioners to address traditional and novel ways to address health concerns, such as diabetes management (Vuong et al. 2012), heart health (Lindsay et al. 2009), cancer prevention (Smith et al. 2009, Kuijpers et al. 2013) and smoking cessation (Bock et al. 2009). People will often look the Internet for information about various types of health services, their rights, and the services and agencies, which can help them. With regard to child health, mothers now can easily use the Internet facilities to contact doctors or nurse to ask about child immunisation services provided by hospital or health centre. Hence, mothers without access to the Internet may not get the benefits of these types of health services. They may unable to get free child immunisation services or to get information about doctor or nurse schedule delivering immunisation services. All of these may have detrimental effect for their children.

Third, lack of access to the Internet may hinder people to share their health issues. Today, social media likes Facebook and Twitter not only give people a platform to connect with other people, but also they can participated in an online support group for people with a similar health or medical issues (Kontos et al. 2014). Mothers often use social media such as Facebook and Twitter to support other mothers in nurturing their children. Moreover, the Internet facilities provide effective tools for sharing knowledge and experience about health and healthcare among individuals within these social media groups. For example, mothers within groups on Facebook and Twitter can share their experiences about their children immunisation or other child healthcare issues such as their experiences with doctors and nurses. They also often use Facebook and Twitter to share coping strategies when they face difficulties to get healthcare services (Kotento 2013).

Evidence in support of health information inequalities in health-related Internet use is building (Lustria et al. 2011, Kontos et al. 2012, Visvanath 2014). However, most of the studies focused at the developed countries, particularly the United State and Western Europe. Evidence of the health consequences of digital divide in developing countries contexts is limited. In developing countries, the Internet provides potentials to bridge the divide of healthcare access across socio-economic groups and geography by providing health information timely and cheaper access. For example, local physicians, community workers and citizens to find information and resources cheaper and faster use the Internet facilities. In archipelago developing countries like Indonesia, the Internet has huge potentials to bridge spatial divide in healthcare access across regions (Sujarwoto \& Tampubulon 2015). For instance, the government can use the Internet for spreading child health information across the country archipelago. However, the promise of the Internet to reduce health inequality may not be realised. An acute inequality in this country may also cause disparity in the Internet access and this may create unhealthy digital divide as a new form of social inequality threating public health in the country.

In this study, we use the case of digital divide and child immunisation access in a low middle income country, Indonesia. The country is often cited as one of the biggest emerging Internet users in the world (Nielsen's Southeast Asian Digital Consumer, 2013). The country was recently acknowledged as one of the biggest users of Twitter and Facebook (Semiocast, 
2013). It is also often cited as an emerging economic success (World Bank, 2008). However, its economic development is characterised by an endemic problem of spatial inequalities (Akita \& Lukman 1995, Hill 1996, Resosudarmo \& Vidyattama 2006, Hill et al. 2008, Yusuf et al. 2014). This study thus considers in some depth whether the growing Internet access in the country can provide bridge in child immunisation access. In order to achieve the aim of this study, annual data from the National Socio Economic Survey (Susenas) 20102013 were studied using instrumental variable analysis to examine the causal mechanisms by which the Internet bridge the disparities in the access of child immunisation services across socioeconomic characteristics of households and districts. The next section discusses the aspects of the Indonesian setting and then the data and methods employed.

\section{Research Method}

Data come from the Indonesian national socio-economic survey (Susenas) 2013 is used to examine the relationship between digital divide and child immunisation access. Susenas is one of the oldest and the best-regarded national representative surveys in developing countries (Friedman \& Levinsohn 2002, Ravallion \& Lokshin 2007); it is also the only one in Indonesia that covers the whole archipelago (Pradhan et al. 2001, Biro Pusat Statistik 2009). Conducted by the government's Central Bureau of Statistics, it has been fielded yearly since 1993 and is representative at the district level. The annual sample size is about 250,000 households (close to 1.2 million individuals) (Biro Pusat Statistik 2009) in all districts in the country.

The survey instrument contains a core questionnaire, which collects information regarding the Internet as well as child immunisation access. The survey also contains information about sociodemographic characteristics of parents and households, their education, labour market activities. We link the Susenas data with the Indonesian Village Potential Census (Podes) 2012 and official statistics. First, Podes 2012 provided information on population, the number of health facilities and health workers (i.e. hospitals, public health centre, doctors and nurses) and telecommunication infrastructures (i.e. mobile phone signal networks and base transceiver station) in all villages within a district, the aggregate of which is calculated for each district. We included health facilities, which provide immunisation for children: hospitals, public health centres (Puskesmas), and integrated health services posts (Posyandu). Second, we use Gini index data 2013 to examine whether district economic inequality affects child immunisation. The Gini index data was retrieved from the government's
Central Bureau of Statistics. Third, we include district spending on health services 2012 in the model to determine whether more districts spending on healthcare services relates to immunisation access. Data on district spending on healthcare services was retrieved from the Ministry of Finance.

\subsection{Measure of digital divide}

Digital divide in this study is measured by a dummy variable indicating a mother access to the Internet $(1=$ have access to the Internet; $0=$ do not have access to the Internet). In the survey, mothers and fathers were asked whether they had accessed the Internet in the last three months with the question "have you accessed the Internet within the last three months?") (Biro Pusat Statistik 2010). The survey defines access to the Internet as a connection made by respondents toward Internet enabling system such as computer terminals, laptop, PC/computers, and mobile devices (Biro Pusat Statistik 2010). The Internet divide is described using the sociodemographic characteristics of individuals who either had or did not have access to the Internet. Differential access to the Internet is related to individuals and their characteristics, including income level, education, employment, age and gender to mention the most important of them (Van Dijk 2012).

\subsection{Measure of child immunisation access}

The key outcome variable is complete child immunisation status among children aged $12-23$ months. We extracted the data on immunisation status from Susenas, in which parents are asked whether their children received each of the basic immunisations or not and the number of doses received for each. Although every immunised child receives an immunisation card recording the date of immunisation and how many they have received, the parent was not obliged to show this card to the Susenas researcher. The data were created based on the answers of the parents. We define complete immunisation status based on a child receiving each of the immunisations in the national EPI schedule (Semba et al. 2007). Children above 2 years old are not included in this study to avoid confusion with the immunisation booster schedule.

We measured child immunisation data as a binary variable $(1=$ received complete basic immunisation; $0=$ not received complete basic immunisation) - complete basic immunisation is important to protect children from vaccine-preventable diseases. Incomplete immunisation (e.g. a child receiving only two shots of DPT immunisation from a series of three) means that immunity is not completely formed. The Indonesia government emphasises the importance of complete basic immunisation to eradicate these diseases and to 
reduce child mortality rate (The Ministry of Health 2013).

\subsection{Individual and district control variables}

We include several individual, household and district control variable which relate to mothers' access to Internet and child immunisation. Individual and household control variables include birth attendants, parents' employment status, age, education, and household socio-economic status. We create a dummy variable for birth attendants ( 1 for a child whose birth was attended by health professional, physicians, midwives and nurses; and 0 for child whose birth was not). Employment status of parents is measured using a dummy variable ( 1 for formal worker and 0 for nonformal worker). We measure parents' education according to the highest level of education attained, differentiated into three levels: primary school, junior high secondary, high school and university (we used primary school as a reference group). Household socioeconomic status is measured using household expenditure over 1 year. Household expenditure variable is entered as a log-transformed continuous variable to make the distribution more symmetric and to reduce the effect of outliers.

A number of district control variables are used to measure variation in local health provision to examine contextual effects. First, we took the number of health facilities and health workers per 1,000 population to measure the availability of healthcare providers, especially in regard to immunisation. We also used the ratio of district health spending on total expenditure and district Gini index to examine whether district economic disparities relate to children immunisation access. The detailed explanation of each variable used in this analysis is presented in appendix two.

\subsection{Instrument variables}

Instruments are elicited not from the Susenas Survey but from the Village Potential Census (Podes) (BPS, 2009). This enhances accuracy or at least reduces measurement error. The use of instrumental variables data from separated sources also alleviates concerns arising from the use of aggregate of individual and household variables using same source in the estimation (Deaton, 2001). In this analysis, we use two instruments; (1) mobile phone signal coverage and (2) number of base transceiver system within districts. We believe that these variables are strongly associated with mother's access to Internet, but it is not directly related to child immunisation.

\subsection{Statistical analysis}

Several steps to analyse the data were used. First, descriptive analyses are used to identify either divergence or convergence between Internet access and child immunisation. Second, logit regression is used to identify initial correlation between mother's access to Internet and child immunisation. Thirdly, instrumental variable analysis is used to examine the causal mechanism between mothers' access to Internet and child immunisation. In this analysis, our empirical model of child immunisation can be represented by the following estimation equation:

$$
H_{i j}=\beta_{0}+C_{j} \beta_{1}+X_{i j} \beta_{2}+S C_{i j} \gamma+\varepsilon_{i j}
$$

Where the subscript $i$ stands for the individual, the subscript $j$ for the districts; $C_{j}$ is a vector of explanatory variables at community, $X_{i j}$ is vector of explanatory variables at individual, $S C_{i j}$ are mother acces to Internet indicator defined at the individual, $\varepsilon_{i j}$ is the disturbance term, and $H_{i j}$ is child immunisation. Standard logistic regression estimates of the coefficient associated with $S C_{i j}$ yield unbiased result if $E\left(S C_{i j} \varepsilon_{i j}\right)$ holds. However, Durlauf and Fafchamps (2005) explain that the orthogonally condition could fail due to reverse causality.

To address this problem, we use instrumental variable estimates (Baum, 2006). The validity of the instrumental variable results will depend on the admissibility of the exclusion restrictions. Therefore, we need to identify variables that satisfy the two necessary conditions for instrument validity. First, they must be both strongly correlated with mother access to Internet ('relevance condition') and orthogonal to the disturbance term of the child immunisation ('orthogonality' condition) (D'Hombres et al., 2010). Instrumental variable estimates also mitigate bias which arises if unobserved mother's characteristics affect both her access to Internet and child immunisation. If we fail to control for these factors and they are also positively related to child immunisation, as is almost certainly the case, regression results will bias the contribution of child immunisation access. To address this issue, we identify variables related to mothers' access to Internet and control for these in the first stage regression. A number of individual, household and district variables, including the instruments associated with mothers' access to Internet, are included in the regression.

\section{Results and Discussion}

Internet growth in Indonesia has shown promising trends in the last two decades. Nielsen's Southeast Asian Digital Consumer (2013) reports that Indonesia's Internet penetration rate is at $21 \%$, growing at $20 \%$ 
annually since 2003. Semiocast (2013) reported that the country was one of the biggest users of Twitter and Facebook after the United States, India and Brazil. In 2012, there were 71.19 million Internet users in Indonesia or about 28 percent of Indonesia's population; these numbers are in line with world Internet growth (Nielsen's Southeast Asian Digital Consumer, 2013). Hence, the Internet provides cost-effective tools for enlarging healthcare information in the country including information about parents' right and healthcare services related to child immunisation.

The first figure in Figure 1 below shows the relationship between Internet use and percentage of children without DPT Immunisation. It shows a strong correlation $(-0.878, p<0.001)$ between increasing Internet access and reducing children without DPT Immunisation in Indonesia between 1996 and 2013. However, this figure do not account for disparities of Internet access and immunisation between rich and poor people. Using Susenas 2013, we account whether these disparities exists (The second figure of Figure 1). It shows a growing gap between poor and rich people in Internet access and access of children who completed immunisation. In 2010, the gap between rich and poor people in child immunisation is about $2 \%$, while the gap of internet access is about $8 \%$. In 2012, the gap widens to about $10 \%$ for child immunisation and $12 \%$ for internet access.
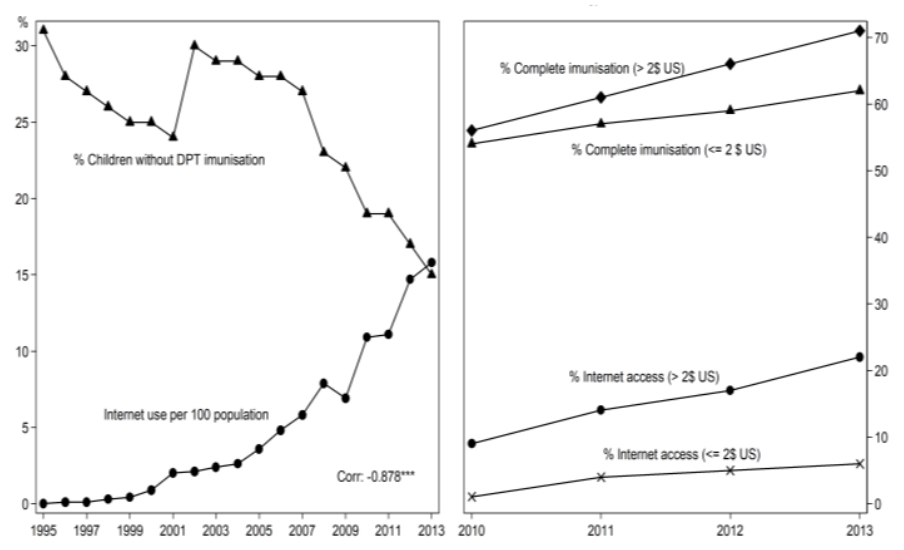

Source: calculated by authors based on World Development Indicators 2014 \& Susenas 2010-2012

Figure 1: Trend of internet use and children immunisation in Indonesia 1995-2013

Not only disparity across socio-economic status, the disparities of Internet and child immunisation in Indonesia are also showed across geographic areas. Sujarwoto \& Tampubolon (2015) found that the geographical disparity in the Internet access in Indonesia widening between people in the city/urban/mainland and countryside/rural/remote islands in the recent years. Our analysis using the Susenas 2013 data shows the marked disparity on the spatial distribution of the Internet access among districts in the country (Figure 2).

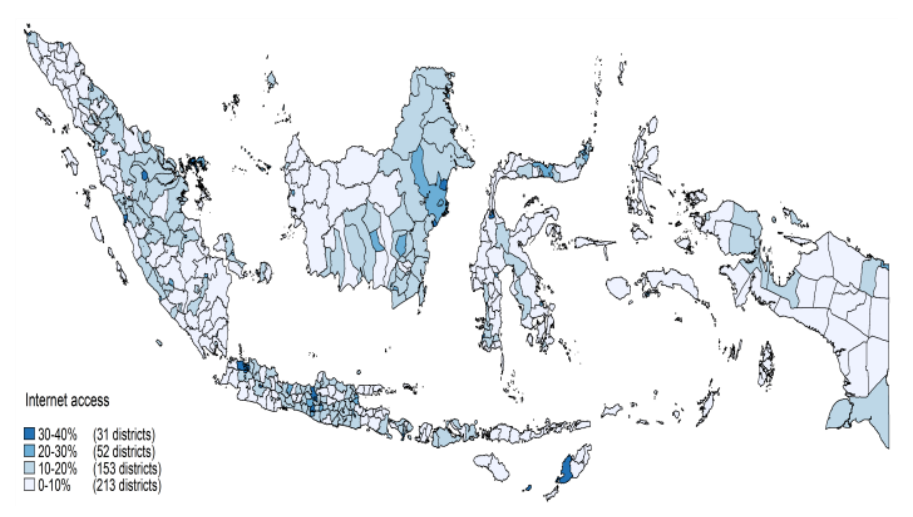

Figure 2: Spatial distribution of Internet access among districts 2013

While it shows that the average of the Internet access among Indonesians is relatively low (below $40 \%$ ), wide geographical disparities of the Internet access among districts appears. It shows that $30-40 \%$ of people within 31 districts able to access the Internet, only below $10 \%$ of people within 213 districts able to access it.

Our analysis using the Susenas 2013 data also shows the marked disparity on the spatial distribution of complete immunisation among districts in the country (Figure 3). More than four of every five children in 53 districts were covered complete immunisation, while in 42 other districts less than two in every five children was covered.

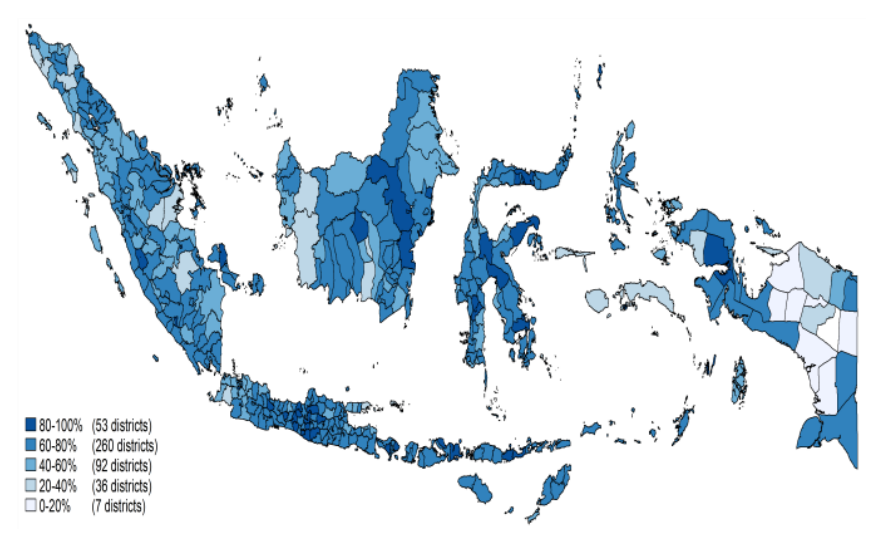

Figure 3: Spatial distribution of child immunisation coverage among districts 2014

The increasing disparities of the Internet and child immunisation access across socio-economic status and among districts in the recent years may signal unhealthy digital divide in Indonesia. Further investigation is needed to examine whether and to what extent the disparity of Internet access in the country is associated with child immunisation access. A deeper analysis of the 
mechanisms explaining by which the Internet can provide bridge or reinforce the disparity of immunisation access would prove a significant contribution to developing countries' efforts to address the effort to achieve universal child immunisation and to reduce the global burden of under-five deaths.

\subsection{Descriptive and simple correlation analysis}

The descriptive statistics (see Table 1) show that almost half of the children in the survey did not receive complete immunisation.

Table 1 Descriptive and bivariate correlation

\begin{tabular}{|c|c|c|c|c|c|}
\hline Variables & Corr. & Mean & Std. Dev. & Min & Max \\
\hline Child complete immunisation & $1.00^{*}$ & 0.64 & 0.48 & 0 & 1 \\
\hline Father has access to Internet & $0.05^{*}$ & 0.11 & 0.31 & 0 & 1 \\
\hline Mother has access to Internet & $0.06^{*}$ & 0.07 & 0.26 & 0 & 1 \\
\hline \multicolumn{6}{|l|}{ Children characteristics } \\
\hline A boy & 0.00 & 0.51 & 0.50 & 0 & 1 \\
\hline Age & $0.37 *$ & 0.51 & 0.50 & 0 & 1 \\
\hline \multicolumn{6}{|l|}{ Mother characteristics } \\
\hline Age & $0.03 *$ & 36.10 & 10.96 & 14 & 98 \\
\hline University education & $0.05^{*}$ & 0.09 & 0.29 & 0 & 1 \\
\hline High school education & $0.06^{*}$ & 0.23 & 0.42 & 0 & 1 \\
\hline Junior high school education & 0.02 & 0.20 & 0.40 & 0 & 1 \\
\hline Have formal jobs & $0.04^{*}$ & 0.11 & 0.31 & 0 & 1 \\
\hline $\begin{array}{l}\text { Have access maternal } \\
\text { services } \\
\text { Father characteristics }\end{array}$ & $0.13^{*}$ & 0.78 & 0.41 & 0 & 1 \\
\hline Age & $0.02 *$ & 40.71 & 11.72 & 17 & 96 \\
\hline University education & $0.05^{*}$ & 0.09 & 0.28 & 0 & 1 \\
\hline High school education & $0.05^{*}$ & 0.27 & 0.45 & 0 & 1 \\
\hline Junior high school education & 0.00 & 0.19 & 0.39 & 0 & 1 \\
\hline Have formal jobs & $0.04 *$ & 0.33 & 0.47 & 0 & 1 \\
\hline \multicolumn{6}{|l|}{ Household characteristics } \\
\hline Have access mobile phone & $0.09^{*}$ & 0.88 & 0.33 & 0 & 1 \\
\hline Live in urban areas & $0.08^{*}$ & 0.40 & 0.49 & 0 & 1 \\
\hline Per capita expenditure & $0.05^{*}$ & 13.08 & 0.61 & 11.34 & 17.09 \\
\hline \multicolumn{6}{|l|}{ District characteristics } \\
\hline $\begin{array}{l}\text { Covered by mobile phone } \\
\text { signal networks }\end{array}$ & $0.12 *$ & 0.91 & 0.17 & 0 & 1 \\
\hline Number of BTS & $0.11 *$ & 51.57 & 46.14 & 0 & 318 \\
\hline $\begin{array}{l}\text { Public hospital/1000 } \\
\text { population }\end{array}$ & $0.06^{*}$ & 0.12 & 0.11 & 0.0 & 0.8 \\
\hline $\begin{array}{l}\text { Health center/ } 1000 \\
\text { population }\end{array}$ & $0.06^{*}$ & 1.22 & 1.01 & 0.02 & 7.11 \\
\hline $\begin{array}{l}\text { Village health Post } / 1000 \\
\text { population }\end{array}$ & $0.07 *$ & 2.77 & 2.29 & 0.00 & 15.91 \\
\hline $\begin{array}{l}\text { Health workers/1000 } \\
\text { population }\end{array}$ & $0.07^{*}$ & 3.03 & 1.90 & 0.02 & 16.86 \\
\hline $\begin{array}{l}\text { Ratio health spending on total } \\
\text { expenditure }\end{array}$ & $0.19^{*}$ & 0.09 & 0.03 & 0.02 & 0.25 \\
\hline Gini Index & $-0.40 *$ & 0.38 & 0.11 & 0.37 & 0.41 \\
\hline
\end{tabular}

Gender inequality in Internet access is shown as only $7 \%$ of mothers have access to Internet, while fathers' access to Internet is about $11 \%$. Fathers' education is higher than mothers' education as the percentage of fathers who educated from high school and university is higher than those of mothers. Likewise, fathers who work at formal job are higher than those of mothers.
The average of per capita household expenditure is 1.3 Million IDR (1.3 Thousand US\$). More than a half of them live in rural areas. Most of them report that they having mobile phone (88\%). The average number of public hospital, health center and village health post per 1000 population is relatively low. Likewise the number of health workers is also low with the average at 3 workers per 1000 population. Most districts are covered by mobile phone signal networks and the average number of based transceiver system is relatively large with 51 per districts. Most districts spent less for health as the ratio of health spending on total expenditure is only $9 \%$.

Simple correlations, without any prior controls, show that mother and father's access to Internet is associated with child immunisation. Parents, households and districts characteristics also associated with child immunisation, in the expected direction. However, these correlations could prove to be spurious as these variables are closely related to the others, for example, if education and employment simultaneously produced higher Internet access. To disentangle these factors, we need to turn to logistic and instrumental variable analysis.

\subsection{Logistic regression and instrumental variable analysis}

We begin by presenting logistic regression and the first stage results of IV analysis to examine the determinants of Internet divide among mothers.

\subsubsection{Determinants of Internet divide among mothers}

Table 2 presents results of logistic regression and firststage of IV regression. The results of both analyses are consistent. Both instruments are strongly associated with mothers' access to Internet. Mothers live in districts which are covered by mobile phone signal networks and base transceiver station have better access to Internet.

Children characteristics are not associated with mothers' Internet access. Older mothers are less likely to access Internet than younger mothers. However, father age is not associated with mother access to Internet. Mothers and fathers' education are strongly associated with Internet access with the highest magnitude association for those with university education. Likewise, mothers and fathers with formal job are more likely to access Internet than mothers working at nonformal jobs. Mothers with access of maternal services are also likely to access the Internet. 
Table 2: Logistic regression and result of first-stage IV regression

\begin{tabular}{|c|c|c|c|c|}
\hline & \multicolumn{2}{|c|}{ Logistic regression } & \multicolumn{2}{|c|}{ IV } \\
\hline & Coef. & Std. Err. & Coef. & Std. Err. \\
\hline \multicolumn{5}{|l|}{ Children characteristics } \\
\hline A boy & 0.099 & 0.047 & 0.003 & 0.002 \\
\hline Age & -0.048 & 0.047 & -0.001 & 0.002 \\
\hline \multicolumn{5}{|l|}{ Mother characteristics } \\
\hline Age & -0.050 & 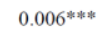 & -0.005 & $0.000^{* * * *}$ \\
\hline University education & 3.374 & 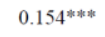 & 0.206 & $0.011^{\text {羊前 }}$ \\
\hline High school education & 2.125 & $0.148^{\text {****** }}$ & 0.012 & $0.003 * * *$ \\
\hline Junior high school education & 1.195 & 0.159 *** & 0.007 & $0.002^{* * * *}$ \\
\hline Have formal jobs & 1.056 & $0.057^{\text {***** }}$ & 0.076 & $0.007^{* * * *}$ \\
\hline Have access maternal services & 0.396 & $0.110^{\text {***** }}$ & 0.160 & $0.002^{\text {****** }}$ \\
\hline \multicolumn{5}{|l|}{ Father characteristics } \\
\hline Father access to Internet & 2.548 & $0.055^{* * * * *}$ & 0.359 & $0.010^{* * * *}$ \\
\hline Age & 0.009 & 0.005 & 0.000 & 0.000 \\
\hline University education & 0.497 & 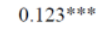 & 0.100 & $0.009^{* * * *}$ \\
\hline High school education & 0.396 & $0.111^{\text {氺氺 }}$ & 0.010 & $0.003^{* * * *}$ \\
\hline Junior high school education & 0.393 & $0.122^{* * * *}$ & 0.006 & $0.002^{* * * *}$ \\
\hline Have formal jobs & 0.278 & $0.053^{* * * *}$ & 0.014 & $0.003 * * *$ \\
\hline \multicolumn{5}{|l|}{ Household characteristics } \\
\hline Have access mobile phone & 2.177 & 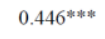 & 0.011 & $0.002^{* * * * *}$ \\
\hline Live in urban areas & 0.145 & $0.016^{\text {****** }}$ & 0.040 & $0.003^{* * * *}$ \\
\hline Per capita expenditure & 0.784 & $0.043^{\text {***** }}$ & 0.034 & $0.003^{* * *}$ \\
\hline \multicolumn{5}{|l|}{ District characteristics } \\
\hline Public hospital/1000 population & 0.897 & 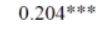 & 0.048 & $0.015^{* * * *}$ \\
\hline Health center/ 1000 population & 0.265 & $0.040^{\text {***** }}$ & 0.005 & $0.002^{* * *}$ \\
\hline $\begin{array}{l}\text { Village health Post } / 1000 \\
\text { population }\end{array}$ & 0.104 & $0.021^{* * * *}$ & 0.100 & $0.001^{* * *}$ \\
\hline Health workers/ 1000 population & 0.138 & $0.019^{* * * *}$ & 0.004 & $0.001 * * *$ \\
\hline $\begin{array}{l}\text { Ratio health spending on total } \\
\text { expenditure }\end{array}$ & 0.103 & 0.074 & 0.004 & 0.005 \\
\hline Gini Index & 0.068 & 0.031 & 0.002 & 0.002 \\
\hline $\begin{array}{l}\text { Instruments } \\
\text { Coverage by mobile signal } \\
\text { networks }\end{array}$ & 1.992 & $0.266^{* * * *}$ & 0.037 & $0.009^{* * * *}$ \\
\hline Number of BTS & 0.134 & $0.001^{* * * * *}$ & 0.098 & $0.000^{* * * *}$ \\
\hline Constanta & -18.912 & $0.792^{*} * *^{*}$ & -0.414 & $0.037^{\text {*** }}$ \\
\hline
\end{tabular}

Households with access to mobile phone are more likely to access Internet than those without mobile phone. As expected, richer households as measured by higher per capita expenditure are more likely to access Internet than poorer households. Households live in urban areas have better Internet access than those live in rural areas. Most districts determinants also show significant association. Mothers live in districts with better health facilities are more likely to access Internet. However, ratio health spending and Gini Index are not associated with Internet access. Next we turn to results of second stage of IV regression in order to examine whether child immunisation is caused by mothers' access to Internet.

\subsubsection{Mothers' access to Internet and child immunisation}

Table 3 presents result of logistic regression and second stage of IV regression. Tests of instrument strength and relevance (Hansen, Lagrange multipliers, Wald, Kleibergen-Paap statistics) reveal their usefulness in identifying the effects of mothers' access to Internet. The Hansen test of over-identifying restrictions does not lead one to reject the orthogonality of our instrument set with respect to the disturbance term with $p$-values greater than 0.667 . The weakness of the set of instruments is rejected with a $p$-value lower than 0.000 . F-statistics, testing the hypothesis that the coefficient on the excluded instruments are all zero in each first-stage estimate, are above the threshold of 10 indicated by Staiger and Stock (1997) as the rule of thumb criterion of instrument weakness. Taken together with the nonrejection of the test of over-identification, this suggests that our set of instruments is reasonable.

Table 3: Logistic regression and result of second-stage IV regression

\begin{tabular}{|c|c|c|c|c|}
\hline & \multicolumn{2}{|r|}{ Logistic regression } & \multicolumn{2}{|r|}{ IV } \\
\hline & Coef. & Std. Err. & Coef. & Std. Err. \\
\hline Mother access to Internet & 0.207 & $0.053^{* * *}$ & 0.812 & $0.231^{* * * *}$ \\
\hline \multicolumn{5}{|l|}{ Children characteristics } \\
\hline A boy & 1.793 & $0.020^{* * * *}$ & 0.339 & $0.021^{* * * *}$ \\
\hline Age & 0.125 & $0.019^{* * * *}$ & 0.113 & $0.020^{\text {**** }}$ \\
\hline \multicolumn{5}{|l|}{ Mother characteristics } \\
\hline Age & 0.011 & $0.002^{* * *}$ & 0.008 & $0.002^{* * * *}$ \\
\hline University education & 0.436 & $0.053^{* * * *}$ & 0.160 & $0.490^{* * * *}$ \\
\hline High school education & 0.341 & $0.032^{* * *}$ & 0.140 & $0.024^{* * *}$ \\
\hline Junior high school education & 0.259 & $0.028^{* * * *}$ & 0.101 & $0.023^{* * * *}$ \\
\hline Have formal jobs & 0.061 & 0.038 & 0.627 & $0.184^{* * * *}$ \\
\hline Have access maternal services & 0.554 & $0.026^{* * * *}$ & 0.109 & $0.018^{* * * *}$ \\
\hline \multicolumn{5}{|l|}{ Father characteristics } \\
\hline Father access to Internet & 0.074 & 0.044 & 0.087 & 0.064 \\
\hline Age & 0.001 & 0.002 & 0.002 & 0.002 \\
\hline University education & 0.121 & $0.005^{* * * *}$ & 0.140 & $0.008^{* * * *}$ \\
\hline High school education & 0.125 & $0.029^{* * * *}$ & 0.110 & $0.035^{\text {****}}$ \\
\hline Junior high school education & 0.068 & $0.028^{* *}$ & 0.065 & $0.024^{* * * *}$ \\
\hline Have formal jobs & 0.006 & 0.023 & 0.113 & $0.041^{* * *}$ \\
\hline \multicolumn{5}{|l|}{ Household characteristics } \\
\hline Have access mobile phone & 0.350 & $0.032^{* * * *}$ & 0.129 & $0.029^{* * * *}$ \\
\hline Live in urban areas & 0.043 & 0.024 & 0.102 & $0.013^{* * * *}$ \\
\hline Per capita expenditure & 0.105 & $0.020^{* * * *}$ & 0.290 & $0.079^{* * * *}$ \\
\hline \multicolumn{5}{|l|}{ District characteristics } \\
\hline Public hospital/1000 population & 0.565 & $0.100^{* * * *}$ & 0.305 & 0.318 \\
\hline Health center $/ 1000$ population & 0.041 & $0.014^{* * *}$ & 0.052 & 0.518 \\
\hline $\begin{array}{l}\text { Village health Post } 1000 \\
\text { population }\end{array}$ & 0.015 & $0.007^{\text {*** }}$ & 0.020 & $0.007^{* * * *}$ \\
\hline Health workers/ 1000 population & 0.107 & $0.007^{* * *}$ & 0.009 & 0.513 \\
\hline $\begin{array}{l}\text { Ratio health spending on total } \\
\text { expenditure }\end{array}$ & 0.291 & $0.034^{* * *}$ & 0.015 & 0.043 \\
\hline Gini Index & -0.064 & $0.014^{* * * *}$ & -0.073 & $0.002^{* * * *}$ \\
\hline $\begin{array}{l}\text { Constanta } \\
\text { Kleibergen-Paap Lm stats (under }\end{array}$ & 0.888 & $0.262^{* * *}$ & 3.732 & $0.919^{\text {***** }}$ \\
\hline id) & & & 16.39 & \\
\hline LM p value & & & 0.000 & \\
\hline Hansen's J & & & 0.185 & \\
\hline $\begin{array}{l}\text { J p value } \\
\text { Cragg-Donald Wald F stats } \\
\text { (weak id) }\end{array}$ & & & $\begin{array}{r}0.667 \\
21.306\end{array}$ & \\
\hline F-test & & & 10.19 & \\
\hline
\end{tabular}

The most important finding from these analyses is that mothers' access to Internet affects child immunisation. The estimated effect of mothers' access to Internet in IV is substantially larger than in the logistic regression estimates and is strongly statistically significant. The magnitude effect of mothers' access to Internet on child immunisation for IV regression results is almost four times larger than logistic regression results. One standard deviation increase in mothers' 
access to Internet is associated with an increase probability of children being immunised by nearly $81 \%$.

The association of other socio-economic characteristics of household and districts show expected results. A boy and older children are likely having completed immunisation than a girl and younger children. Mothers and fathers who have only completed primary education or less are less likely to immunise their children than those with a higher level of education, while younger mothers have a lower probability of immunising their children than older mother. Likewise, parents' with formal job are likely to immunise their children than those with non-formal job. Mothers' who use maternal care during her pregnancy are likely to immunise their children than those who do not use maternal care. Interestingly, father access to Internet is not associated with child immunisation.

Households that use mobile phone are likely to immunise their children than those without mobile phone. Children who live in urban areas and those of better-off families are more likely to be immunised.

Increasing the number of village health post by one per 1,000 of the population improves the probability of children receiving complete immunisation. However, adding a hospital, health centre, and health workers has no significant effect. The local health spending as a proportion of total district spending has no significant effect on immunisation status. Children live in district with higher income inequality are less likely to be immunised.

\section{Conclusion}

Increasingly use of Internet as source of health information in developed and developing countries raising concern about unhealthy digital divide (Viswanath 2014). Recent studies in developed country found that unequal access of the Internet widen the disparities of health and access of healthcare of individuals and communities (Wyatt et al. 2005, Korp 2006, Viswanath 2014). This study examines whether such health and healthcare disparities associated with Internet access are also found in the contexts of developing country. Indonesia provides interesting case not only because it's growing use of Internet but also deep disparities of health development among districts in the country.

The main findings indicate trend of widening disparities across socio-economic status and geographical areas in Internet and child immunisation access. Mothers with Internet access are positively and significantly associated with child immunisation. These results are being true with logistic regression as well as when relying on IV estimations. All instruments are highly correlated with mothers' access to Internet; test of their strength and relevance also reveal their usefulness to mitigate bias estimate of the relationship between mothers' access to Internet and child immunisation.

This finding may suggest that mothers of young children likely use Internet to search information related to their children health. Hence, they are more likely aware to bring their children to village health post, health centre, and hospital to immunise them since they have better information and knowledge on the vital role of child immunisation for children health than those without access of Internet. This is particularly importance for Indonesia in which most district governments have limited ability to distribute health information through traditional tools. Hence, the Internet provides efficient tools to distribute health information to wider areas. However, as the Internet can only be accessed by mothers from higher socioeconomic status, health benefits of Internet is only gained by rich and educated mothers. Mothers with lack access to the Internet may not get such health benefits and therefore they still have less awareness and knowledge of the importance of immunisation. They may also have less information to get immunisation services for their children. Hence, the Internet divide among mothers of young children likely reinforce divide in child immunisation access.

The contrast finding of mothers and fathers' access to Internet and their children immunisation may confirm that women are higher health information seekers than men, particularly regarding their pregnancy and their children health. Berhardt and Felter (2004) found that women appear to be high information seekers during pregnancy and the first few years following delivery, and this period represents an important window of time for providing online health information. The most common reasons that mothers of young children reported going online for health information are either they are wanting to learn more about diagnosing and treating specific pediatric health conditions nor they are seeking out advice and support on parenting issues and development (Susannah et al. 2000).

The significant association of instruments explains channels for bridging digital divide among mothers as well as disparities of child immunisation. Hence, enlarging telecommunication infrastructure particularly mobile phone signal coverage and distribution of base transceiver station across country archipelago will bridge the divide. These findings relate to prior studies which also point out those disparities of telecommunication infrastructures in Indonesia is one of the main factors of digital divide (Sujarwoto \& Tampubolon 2015). Hence, our findings show that telecommunication infrastructure disparities may be not only related to disparity in Internet access but also disparity in child immunisation. 
Other findings confirm prior studies. Parents' education and household expenditure are strong predictors of child immunisation, indicating the importance of human and economic capital of parents for achieving child health (WHO, 1998). The positive association of mobile phone use on child immunisation confirms that this type of information and communication technology can be used as an effective communication tool for increasing health and healthcare in poor and developing countries. With regard to districts, the insignificant association of hospital and health centres as well as health workers on child immunisation indicate lack of district capacity in delivering health services for child immunisation (Maharani \& Tampubolon 2014). Likewise, the lack association of district public health spending on child immunisation indicate that district lack health financing capacity in managing health decentralisation. The positive association of village health centre (posyandu) suggests that enlarging such type of health facilities will effectively improve children for receiving full immunisation. The negative association of Gini Index and child immunisation confirms harm effect of economic inequality on children health.

The main limitation of this study is that we do not have any information about type of information that mothers' and fathers' access to the Internet. The survey is only asking about whether mothers and fathers have access to the Internet, but it is not asking about what health information that they access. Thus, future study needs to explore type of health information and health online facilities that parents especially mothers of young children in poor and developing countries look for seeking. Second, we are unable to control for all unobservable features of districts that might simultaneously generate relatively high levels of mothers' access to Internet and better access to child immunisation. We try to include a number of sociodemographic characteristics within districts that potentially affect child immunisation. However, unobservable features (such as climate) might drive both mothers' access to Internet as well as their access to child immunisation.

Despite these limitations, the findings have important implications, both for the literature and for the efforts of reducing disparities of access to child immunisation in a developing country. First, while prior studies show the consequences of digital divide in developed countries (Wyatt et al. 2005, Korp 2006, Viswanath 2014), we show that these negative consequences of digital divide also occur in a developing country. Our empirical study shows that the difference of child immunisation access between mothers with access to the Internet and without access to the Internet. Secondly, the fact that mothers' access to the Internet improves child immunisation suggests that reducing child immunisation disparities in Indonesia through enlarging the distribution of online health information, especially for women as well as rural and remote districts are vital.

\section{References}

Akita, T. and Lukman, R.A. (1995). Interregional inequalities in Indonesia: a sectoral decomposition analysis for 1975-92. Bulletin of Indonesian Economic Studies, 31(2),61-8.

Barry, M (2013). Internet access is a vital healthcare tool. Reuters news.

Baum, C. F. (2006). An introduction to modern econometrics using Stata. Texas: Stata Press

Bernhardt, J.M. (2000). Health education and the digital divide: Building bridges and filling chasms. Health Education Research, 15:527-531.

Bernhardt, J.M. and Felter, EM (2004). Online pediatric information seeking among mothers of young children: Results from a qualitative study using Focus Groups. Journal of Medical Internet Research, 6(1).

Biro Pusat Statistik. (2009). Susenas guide book 2009, Jakarta: BPS Indonesia.

Biro Pusat Statistik. (2010). Susenas guide book 2010, Jakarta: BPS Indonesia.

Brendryen, H. and Kraft, P. (2008) Happy ending: a randomized controlled trial of a digital multi-media smoking cessation intervention. Addiction, 103:47884.

Curioso, W. (2006). New technologies and public health in developing countries: The cell PREVEN Project. In M. Murero, and R. Rice (Eds.), The Internet and Health Care: Theory Research and Practice. Mahwah, NJ: Lawrence Erlbaum Associates.

D'Hombres, B., Rocco, L., Suhrcke, M., and McKee, M. (2010). Does social capital determine health? Evidence from eight transition countries. Health Economics, 19(1), 56e74.

Deaton, A. and Zaidi, S. (2002). Guidelines for constructing consumption aggregates for welfare analysis. Washington DC: World Bank.

Donner, J. (2004). Innovations in mobile-based public health information systems in the developing world: An example from Rwanda, Mobile Technologies and Health: Benefits and Risks. Udine, Italy.

Duflo, E. and Udry, C (2004). Intra-household resource allocation in Cote d'Ivoire: Social norms, separate accounts and consumption choices. NBER Working Paper 10498.

Durlauf, S., and Fafchamps, M. (2005). Social capital. In S. Durlauf, and P. Aghion (Eds.). Handbook of economic growth, Vol. IB, . Amsterdam: North Holland.

Hall, AK., Bernhardt, JM, Dodd, V., and Vollrath, MW (2014) The digital health divide: Evaluating online health information access and use among older adults. Health Education Behavior, 42(2): 202-209. 
Hill, H. (1996). The Indonesian economy since 1966: Southeast Asia's emerging giant. Cambridge: Cambridge University Press.

Hill, H., Resosudarmo, B., and Vidyattama, Y. (2008). Indonesia's changing economic geography. Bulletin of Indonesian Economic Studies, 44(3), 407-35.

Hoddinott, J. and Haddad, L. (1995). Does female income share influence household expenditures? Evidence From C^ote D'Ivoire. Oxford Bulletin of Economics and Statistics 57 (1): 77-96.

Jackson, P.B. (2005) Health inequalities among minority populations, Journal Gerontology B Psychol Sci Soc Sci, 60 (2): S63-S67.

Kaplan, W.A. (2006). Can the ubiquitous power of mobile phones be used to improve health outcomes in developing countries? Globalization and Health, 2(9), Open Access (pp.1-14).

Kawachi I. (2000) Income inequality and health. In: Berkman LF, Kawachi I, eds. Social epidemiology. New York, NY: Oxford University Press.

Kawachi, I and Kennedy, BP. (2003) The health of nations. New York, NY: The New Press

Kontos, E., Blake, KD., Chou, WY, Prestin, A. (2012) Predictors of eHealth usage: Insights on the digital divide from the health information national trends survey. Journal of Medical Internet Research, 16(7).

Kotento, J. (2013, April 18). The doctors will see you now: How the Internet and social media are changing healthcare. Retrieved from http://www.digitaltrends.com/social-media/theinternet-and-healthcare

Kuijpers, W., Groen, W.G., Aaronson, N.K. and van Harten, W.H. (2013) A systematic review of Web-Based Interventions for patient empowerment and physical activity in chronic diseases: Relevance for Cancer Survivors. Journal of Medical Internet Research, 15(2).

Lindsay, S., Smith, S., Bellaby, P. and Baker, R. (2009). The health impact of an online heart disease support group: A comparison of moderated versus unmoderated support, Health Education Research, 24(4) 646-654.

Lindsay S, Smith S, and Bell, F. (2007) Tackling the digital divide: Exploring the impact of ICT on managing heart conditions. Journal Information Communication Society, 10: 95-114.

Lindsay S, Bellaby P, and Smith S. (2008) Enabling healthy choices: is information and communication technology the highway to health improvement? An Interdisciplinary Journal for the Social Study of Health, Illness and Medicine, 12: 313-31.

Maharani, A., and Tampubolon, G. (2014) Has decentralisation affected child immunisation status in Indonesia? Global Health Action. DOI:10.3402/gha.v7.24913

Marmot, M. (2005). Social determinants of health inequalities, Lancet, 365(9464), 1099-1104

Nielsen's Southeast Asian Digital Consumer. (2013). Southeast Asian digital consumer habits. Singapore: Nielsen Company.
Norris, P. (2001), Digital divide: civic engagement, information poverty, and the Internet worldwide, New York: Cambridge University Press

Olson, ME, Elliot, BA., and Renier, C.M. (2010) Impact of income and income inequality on infant health outcomes in the United States. PEDIATRICS, 126.

Resosudarmo, B.P. and Vidyattama, Y. (2006). Regional income disparity in Indonesia: a panel data analysis. ASEAN Economic Bulletin, 23(1), 31-44.

Ravallion, M and Lokshin, M. (2007). Lasting impacts of Indonesia's financial crisis, Economic Development and Cultural Change, 56(1), 27-56.

Semba RD, de Pee S, Berger SG, Martini E, Ricks MO, and Bloem MW. (2007). Malnutrition and infectious disease morbidity among children missed by the childhood immunisation program in Indonesia. Southeast Asian J Trop Med Public Health, 38: 120129.

Semiocast, (2013). Internet growth in Asia. France: Semioscast.

Shelton, N., Birkin, M. and Dorling, D. (2007). Where not to live: geographic inequalities in mortality in Britain, 1981-2000, Health and Place, 12 (4), 557-569

Smith PJ, Humiston SG, Marcuse EK, Zhao Z, Dorell CG, Howes C, and Hibbs B. (2011) Parental delay or refusal of vaccine doses, childhood vaccination coverage at 24 months of age, and the health belief model. Public Health Reports, 126 (Suppl 2):S135S146

Smith, A, Yarwood, J and Salisbury, DM (2007). Tracking mothers' attitudes to MMR immunisation 19962006. Vaccine; 25: 3996-4002.

Subramanian, SV and Kawachi, I, 2004. Income inequality and health: What have we learned so far? Epidemiol $\operatorname{Rev}(26)$ 78-91

Sujarwoto, S. and Tampubolon, G. (2015). Spatial inequality and Internet divide in Indonesia. Forthcoming Telecommunication Policy.

Susannah, F, Rainie L, Horrigan J, Lenhart A, Spooner T, and Burke M. (2000). The online health care revolution: How the web helps Americans take better care of themselves. Washington DC: Pew Internet and American Life Project.

Stafford, M., Duke-Williams, O. and Shelton, N (2008) Small area inequalities in health: Are we underestimating them? Social Science and Medicine, 67(6) 891-899.

Thomas, D. (1990). Intra-household resource allocation: An inferential approach. Journal of Human Resources, 25(4): 635-664.

Valadez, J.J. and Weld, L.H. (1992) Maternal recall error of child vaccination status in a developing nation. American journal of public health, 82:120-2.

Van Dijk, J.A.G.M. (2012). The evolution of the digital divide: the digital divide turns to inequality of skills and usage. Digital Enlightenment Yearbook 2012.

Viswanath, K (28 January 2014) An unhealthy digital divide. Harvard TH Chan School of Public Health News.

Viswanath K, Kreuter MW. (2007). Health disparities, communication inequalities, and eHealth. Am J Prev Med, . 32(5 Suppl):S131-S133 
Vuong, AM., Huber, JC., Bolin, JN., Ory, MG., Moudouni, DM., Helduser, J., Begaye, D., Bonner, TJ., and Forjuoh, SN. (2012). Factors affecting acceptability and usability of technological approaches to diabetes self-management: A Case Study. Diabetes Technol Ther, 14(12): 1178-1182.

Wang JY, Bennett K, and Probst J. (2011). Subdividing the digital divide: differences in internet access and use among rural residents with medical limitations. $J$ Med Internet Res, 13(1):e25

Weeks, JR., Hill, AG. and Stoler, J. (2014) Spatial inequalities: Health, poverty, and place in Accra, Ghana, GeoJournalLibary: Springer Netherlands.

WHO (2009). State of the world's vaccines and immunization, 3rd ed. Geneva: World Health Organization.

World Bank. (2008). Indonesia economy: strong performance but risks lie ahead. Jakarta: World Bank.

World Bank (2008). Investing in Indonesia's health: challenges and opportunities for future public spending. Washington DC:World Bank.

World Bank (2014) Internet and development: Preparing the World Development Report 2016. Washington DC: World Bank

Yusuf, A.A, Sumer, A. and Rum, I.A. (2014). Twenty years of expenditure inequality in Indonesia 1993-2013, Bulletin of Indonesian Economic Studies, 50(2), 243254. 